\title{
Dinâmica da composição e cobertura de espécies de macrófitas aquáticas e a escolha de indicadores de impacto ambiental em um rio com ecoturismo
}

\author{
Composition and coverage dynamics of aquatic macrophytes species and \\ the choose of environmental impact indicators in a river with ecotourism \\ tour
}

Antônio dos Santos Junior ${ }^{1(*)}$

Marco de Barros Costacurta ${ }^{2}$

\section{Resumo}

Estudos sobre ecologia de macrófitas aquáticas em ambiente natural no Brasil são relativamente escassos. Anualmente, um grande número de turistas é recebido para a prática da flutuação nas águas do rio Sucuri, Bonito, Estado de Mato Grosso do Sul. Os objetivos deste estudo foram: (1) descrever a composição e a cobertura relativa das espécies de macrófitas aquáticas no Rio Sucuri,(2) investigar o padrão de desbaste das macrófitas aquáticas no decorrer do ano e (3) eleger espécies com potencial de serem indicadoras de impacto ambiental da atividade turística. Foi empregado o método do intercepto em linha modificado para amostrar a composição e cobertura relativa das espécies de macrófitas aquáticas. Foram identificadas dezessete espécies macrófitas aquáticas. Durante o estudo foram observadas variações na composição e cobertura relativa das espécies de macrófitas aquáticas. Gomphrena elegans Mart. foi a espécie dominante em termos de cobertura relativa. Duas espécies apresentaram as características consideradas importantes para a indicação de impactos da atividade turística, considerando os resultados de cobertura relativa, frequência e desbaste: Nymphaea gardneriana Planch. e Myriophyllum aquaticum (Vell.) Verdc. Assim, é sugerido que o monitoramento dos impactos do turismo sobre as macrófitas seja realizado na sua organização biológica populacional.

Palavras-chave: impacto ambiental; ecoturismo; rio Sucuri; Planalto da Bodoquena.

I Dr.; Biólogo; Professor Adjunto do Departamento de Biologia do Centro Universitário Luterano de JiParaná; Endereço: botton Av. Engenheiro Manfredo Barata Almeida da Fonseca, 762, Bairro Jardim Aurélio Bernardi, Caixa Postal: 27I, CEP: 76.907-438, Ji-Paraná-Rondônia-Brasil; E-mail: tonhobio@hotmail.com (*) Autor para correspondência.

2 MSc.; Biólogo; E-mail: costacurtamb@yahoo.com.br 


\section{Abstract}

Ecologic studies around aquatic macrophytes in natural environment in Brazil are relatively scarce. Annually, many tourists have been received for floating practice on Sucuri river, in Bonito, Mato Grosso do Sul state. The aims of this research were: (1) describing the composition and the relative coverage of aquatic macrophytes in Sucuri river, (2) investigating the pattern of thinning of aquatic macrophytes during the year, and (3) electing species, such as indicators of environmental impact done by tourism. Intercept line method modified was used in order to sample the composition and the relative coverage data of aquatic macrophytes. Thus, 17 aquatic macrophyte species were identified. Meanwhile, research changes were observed at the composition and the relative coverage data of aquatic macrophytes species. Gomphrena elegans Mart. was the dominant species in relative coverage terms. Two species show the potential indicator of the environmental impacts of tourism, considering the results of relative coverage, frequency and thinning: Nymphaea gardneriana Planch. and Myriophyllum aquaticum (Vell.) Verdc. Thus, it is suggested that the impact of tourism must be monitored by the analysis of macrophytes populations.

Key words: environmental impact; ecotourism; Sucuri river; Bodoquena plateau.

\section{Introdução}

As plantas conhecidas por macrófitas aquáticas são representadas por um grupo de organismos taxonomicamente diverso, que exibe um amplo espectro de formas de vida e, em função desta propriedade, encontramos como pertencentes a esta generalização algas (ex. Gênero Chara L. e Nitella C. Agardh), samambaias (ex. Gêneros Acrostichum L. e Salvinia Ség.) e plantas com flores (ex. Gêneros Eichornia Kunth, Ludwigia L. e Echinodorus Rich. ex Engelm.) (POTT, 1999; POTT e POTT, 2000a; ROCHA et al., 2007; MARTINS et al., 2008). Estes organismos têm sido objeto de controvérsia, envolvendo tanto a definição biológica do grupo, como seu valor ecológico.

Adotou-se aqui a definição proposta por Irgang e Gastal (1996). Para estes autores, macrófita aquática é toda planta cujas partes fotossinteticamente ativas estão submersas ou flutuantes por alguns meses ou permanentemente, a cada ano, e que são visíveis a olho nu. Deste modo, englobam também as plantas de margens que tem relação com água em abundância. Analisando esta definição constata-se o amplo espectro de ambientes em que esta forma de vida pode ocorrer. As macrófitas aquáticas podem ser encontradas crescendo às margens de rios e reservatórios ou dentro dos mais diversos ambientes aquáticos, empregando diferentes mecanismos de adaptação para sobrevivência e desenvolvimento (DOMINGOS et al., 2005; BENTO et al., 2007; NEVES e SANTOS, 2008).

Quanto ao valor ecológico das macrófitas aquáticas, aparentemente, há uma tendência para a valoração econômica dos impactos gerados pelo crescimento exponencial destas plantas em reservatórios artificiais destinados à geração de energia hidrelétrica, em detrimento da importância 
destas plantas para a melhora da qualidade da água pela remoção de compostos tóxicos e poluentes (e.g. metais pesados) (POMPEO, 2008), bem como para a fauna aquática dela dependente. Facilmente encontramse na literatura ecológica estudos que investigaram a composição de espécies de macrófitas aquáticas e sua a variação espacial e temporal em reservatórios artificiais, os impactos do crescimento da biomassa destas plantas na geração de energia e as condições físicas e biológicas que promoveram o crescimento exponencial de suas populações em reservatórios artificiais (MARTINS et al., 2003; CARVALHO et al., 2003, 2005; DOMINGOS et al.,2005; CAVENAGHI et al., 2005; PITELLI et al., 2008; MARTINS et al., 2008).

Contudo, a importância ecológica das macrófitas aquáticas não deve ser medida somente pelos obstáculos causados às atividades humanas em ambientes artificiais ou domesticados. A valoração das macrófitas aquáticas no ecossistema deve considerar o importante papel ecológico delas como fonte de alimento, local de reprodução e refúgio para diversas espécies de animais. Por exemplo, as partes submersas das macrófitas aquáticas formam um hábitat complexo, composto de caules e raízes que são colonizados por perifíton, moluscos, insetos e peixes (FROEHLICH, 1999; PEIRÓ e ALVES, 2006; MARTELLO et al., 2008). A presença destes vegetais no ecossistema aquático permite a existência de comunidades de animais mais diversas do que aquelas de locais onde essas plantas não ocorrem, principalmente, em razão do aumento da complexidade estrutural do ambiente. Este aumento de complexidade permite que uma maior diversidade de modos de vida habite um dado ambiente aquático (FROEHLICH, 1999).
Estudos sobre ecologia de macrófitas aquáticas no Brasil são relativamente escassos (THOMAS e BINI, 2003; POMPEO, 2008), especialmente em ambiente natural. Segundo Pompeo (2008) diversas são as justificativas para o aumento de estudos sobre este componente do ecossistema aquático, porém a vantagem é basicamente uma: os estudos destes organismos aquáticos não só ampliará o conhecimento sobre diversos aspectos de sua ecologia, como constituirá base para aplicações em programas de monitoramento e manejo.

Nas águas do rio Sucuri, Bonito, Estado de Mato Grosso do Sul, já foram registradas 23 espécies de macrófitas aquáticas (POTT, 1999; POTT e POTT, 2000b). Neste rio é desenvolvida uma atividade turística denominada flutuação, na qual um grupo de turistas acompanhados por um guia flutua nas águas do rio, no sentido de sua nascente em direção à foz no rio Formoso (COSTACURTA, 2005). Devido ao grande número de turistas recebidos anualmente para a prática da flutuação nas águas do rio Sucuri (cerca de 20.000 turistas ao ano), este estudo teve como objetivos (1) descrever a composição e cobertura relativa das espécies de macrófitas aquáticas no Rio Sucuri, (2) investigar o padrão de desbaste das macrófitas aquáticas no decorrer do ano e (3) eleger espécies com potencial de serem indicadoras de impacto ambiental da atividade turística sobre o ambiente aquático do Rio Sucuri.

\section{Material e Métodos}

Para a classificação de Köppen, na região do Planalto da Bodoquena, Estado de Mato Grosso do Sul, predomina o clima Tropical Úmido (Aw) que se caracteriza por apresentar uma estação seca acentuada, de junho a setembro (Figura 1). As precipitações 


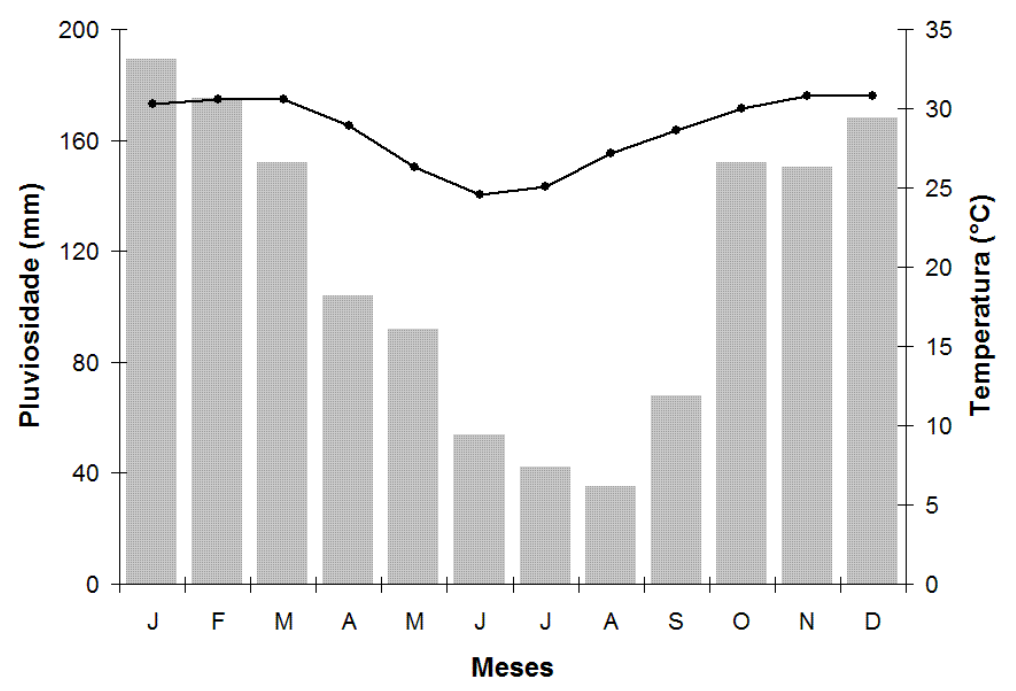

Figura I. Pluviosidade (barras) e Temperatura máxima (linha) durante os meses do ano de 2008

Nota: Dados obtidos pelo monitoramento climático realizado pelo sistema gerenciamento ambiental do rio Sucuri, RPPN Fazenda São Geraldo, Bonito (MS).

anuais estão entre 900 e 1.800 milímetros, concentrados entre novembro e janeiro e umidade relativa do ar de $80 \%$, temperatura média do mês mais frio é superior a $15^{\circ} \mathrm{C}$ e menor que $20^{\circ} \mathrm{C}$ (REATTO et al., 1998; MENDES et al., 2003). Em função da concentração das chuvas num curto período do ano, os rios de cabeceira na região apresentam grande variação na altura da coluna d'água (Figura 2).

A região de Bonito, onde se encontra o rio Sucuri, está localizada em uma área de contato de diferentes tipos e grupos litológicos, com intensos processos tectônicos, implicando na produção de paisagens particulares. Está assentada basicamente sobre rochas carbonáticas - calcários e dolomitos - das Formações Cerradinho e Bocaina, do Grupo Corumbá no topo, e rochas do Grupo Cuiabá, na base, arcabouço geológico do Planalto da Bodoquena (BRASIL, 1982; BOGGIANI, 1999).
O planalto da Bodoquena é a área de cabeceira dos rios Salobra, Prata, do Peixe e Formoso, afluentes da margem esquerda do rio Miranda. O rio Sucuri é um dos afluentes do rio Formoso e localiza-se sob as coordenadas geográficas $21^{\circ} 15^{\prime} 58^{\prime \prime} \mathrm{S}$ e $56^{\circ} 33^{\prime}$ 30 "W. Este pequeno rio possui pouco mais que $1.800 \mathrm{~m}$ de extensão, variando de doze a quarenta metros de largura, água cristalina e rica em biodiversidade subaquática.

As águas dos rios da região do Planalto da Bodoquena são cristalinas devido à rápida sedimentação de partículas em suspensão na coluna d'água. Essa sedimentação é provocada pela conjugação entre o cálcio e/ ou magnésio dissolvido com estas partículas, tornando-as pesadas e as carregando para o fundo do leito (BOGGIANI, 1999). A transparência da água somada à baixa velocidade da água e ao teor de nutrientes disponíveis promove o crescimento de grande diversidade de macrófitas aquáticas 


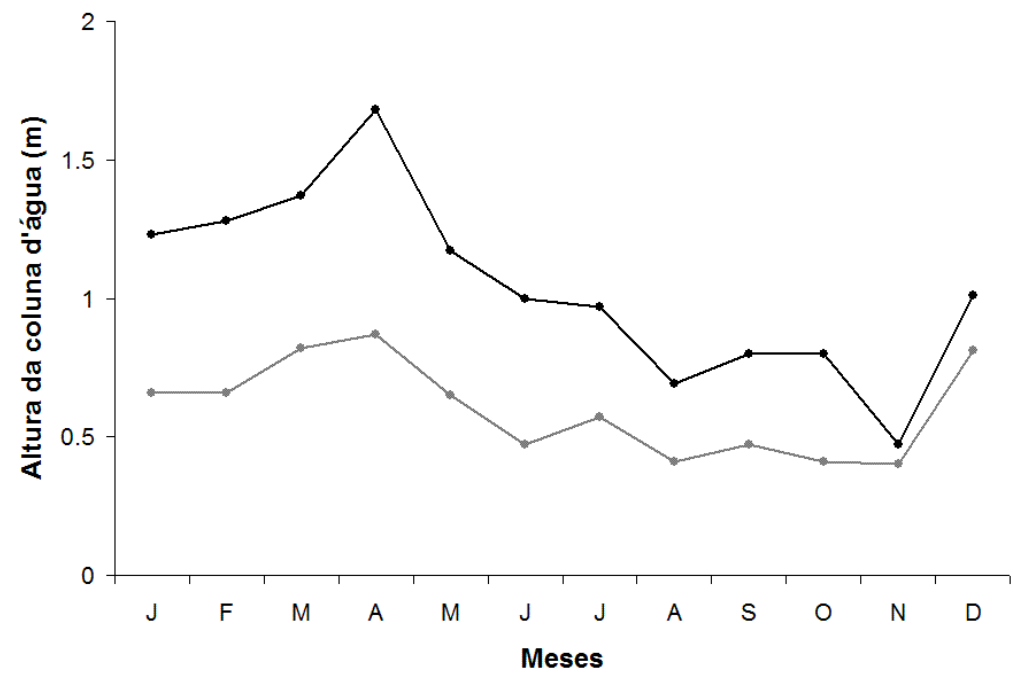

Figura 2. Variação da altura da coluna d'água na cabeceira (linha cinza) e na foz (linha preta) do rio Sucuri durante os meses do ano de 2008.

Nota: Dados obtidos pelo monitoramento climático realizado pelo sistema gerenciamento ambiental do rio Sucuri, RPPN Fazenda São Geraldo, Bonito (MS).

no rio Sucuri, tornando esse ambiente em um verdadeiro “jardim submerso", de beleza cênica ímpar, como descrito por ScreminDias et al. (1999).

A vegetação do rio Sucuri é constituída de bancos emergentes de plantas aquáticas, quase impenetráveis, ao longo do seu percurso, e plantas submersas no fundo (POTT, 1999). Dentre os procedimentos de amostragem empregados em estudos de macrófitas aquáticas destaca-se o levantamento da vegetação através de interceptos em linha, técnica desenvolvida originalmente para estudos de formações campestres (CANFIELD, 1941; BROWER et al., 1997). O método consiste em traçar linhas sobre a vegetação a ser amostrada e anotar a projeção de cada espécie sob as mesmas (ou seja, o comprimento da linha que é interceptada por uma espécie) (FELFILI et al., 2005). A cobertura é expressa pela porcentagem da área coberta pela projeção da parte aérea das plantas e pode ser entendida como uma medida de abundância. É recomendável que seja registrada e inserida nos cálculos a extensão de área descoberta (exposta à luz direta) (DURIGAN, 2003).

O estudo foi desenvolvido empregando quatro linhas de amostragem distribuídas sistematicamente a distâncias de 400 metros ao longo do rio Sucuri, RPPN Fazenda São Geraldo, Bonito, MS. A coleta de dados sobre as macrófitas aquáticas foi delineada para permitir que todos os hábitos de macrófitas fossem amostrados, desde plantas epífitas até submersas fixas (POTT, 1999; POTT e POTT 2000b), bem como a área livre de cobertura de macrófitas para a prática da flutuação pelos turistas. As linhas foram demarcadas de modo permanente, com orientação perpendicular ao eixo do rio. Assim, amostramos as espécies de macrófitas aquáticas em um gradiente ecológico (BROWER et al., 1997) de profundidade 
e de tempo de residência de água. Como o rio apresenta diferentes larguras, as linhas acabaram por ter diferentes tamanhos, sendo $42,31,14,4$ e $25,6 \mathrm{~m}$, totalizando $113 \mathrm{~m}$ lineares de extensão da superfície do rio amostrada.

A cobertura relativa foi calculada empregando a fórmula: $\left(e_{\mathrm{i}} / \mathrm{E}\right)^{*} 100$ (onde $e_{\mathrm{i}}=$ soma da projeção da cobertura de todos os indivíduos da espécie i sob as linhas de amostragem em metros lineares; $\mathrm{E}=$ extensão total de amostragem em metros lineares).

A frequência relativa foi calculada empregando a fórmula $\left(l_{\mathrm{i}} / \mathrm{L}\right) * 100$ (onde: $l_{\mathrm{i}}=$ número de linhas de amostragem em que a espécie i foi amostrada; $\mathrm{L}=$ número total de linhas de amostragem).

Para avaliar o padrão de desbaste de macrófitas foi realizado um trajeto de flutuação no rio Sucuri, no qual se coletou todos os ramos desbastados de macrófitas que estavam presos a troncos e galhos na coluna d'água do rio. Assim, foram amostradas as espécies de macrófitas aquáticas sujeitas ao desbaste durante o período entre amostragens. A coleta de dados teve uma periodicidade bimestral durante o período de um ano (de outubro de 2007 a agosto de 2008).

\section{Resultados e Discussões}

\section{Composição e cobertura relativa de espécies de macrófitas aquáticas}

Foram identificadas dezessete espécies macrófitas aquáticas, pertencentes a quatorze famílias (Tabela 1). A composição de espécies e os valores de coberturas relativas apresentaram certa variação ao longo do estudo. Assim, foi possível observar uma estrutura de comunidade de macrófitas aquáticas diferente a cada bimestre no rio Sucuri (Figura 3).

A espécie dominante, em termo de cobertura relativa, foi Gomphrena elegans Mart. durante todo o tempo de estudo. Esta espécie é seguida de longe por um grupo composto pelas espécies Potamogeton illinoensis Morong, Rhynchospora corymbosa (L.) Britton e Acrostichum danaeifolium Langsd. \& Fisch. Estas espécies destacam-se como um grupo que apresentou valores intermediários de cobertura relativa durante o estudo. Todas as demais espécies apresentaram pequenos valores de cobertura, quando não estiveram ausentes na amostragem (Figura 3).

Os valores de cobertura relativa de G. elegans Mart. estiveram sempre entre 3040\%. O espaço sem cobertura por macrófitas (SC), isto é, a parte da lâmina d'água do rio Sucuri livre de macrófitas variou entre 23-33\%, demonstrando que a superfície do rio é dominada por macrófitas aquáticas. Os valores de cobertura de G. elegans Mart. somados ao trecho da lâmina d'água livre de macrófitas aquáticas representam cerca de $60 \%$ da superfície do rio, assim, as demais espécies estão restritas ao pequeno espaço disponível para colonização (Figura 3).

O padrão de colonização para as espécies que apresentaram pequena cobertura relativa pode ser descrito pela não formação de extensas manchas de macrófitas aquáticas (i.e. bancos sensu POTT, 1999). Algumas espécies estiveram presentes em todo o período de estudo, como Nymphaea gardneriana Planch., porém sempre com variação nos valores de cobertura relativa. Outras não foram detectadas em todos os meses de amostragem, como Polygonum cf. acumminatum Kunth (Figura 3).

Pode-se observar que existem espécies que ao longo do ano estão presentes em todo 
Tabela I. Espécies de macrófitas aquáticas amostradas e suas respectivas frequências de ocorrência ao longo do monitoramento do rio Sucuri (out/2007-ago/2008), RPPN Fazenda São Geraldo, Bonito (MS). Os nomes científicos estão redigidos conforme o Catálogo de Plantas e Fungos do Brasil (FORZZA et al. 2010).

\begin{tabular}{|c|c|c|c|c|c|c|}
\hline \multirow{2}{*}{ Família /Espécies } & \multicolumn{6}{|c|}{ frequência de ocorrência (\%) } \\
\hline & out & dez & fev & abr & jun & ago \\
\hline \multicolumn{7}{|l|}{ CHAROPHYCEAE } \\
\hline $\begin{array}{l}\text { Chara fibrosa C. Agardh ex Bruzelius emend R.D. } \\
\text { Wood }\end{array}$ & 50 & 50 & 50 & 50 & 100 & 25 \\
\hline $\begin{array}{l}\text { Chara rusbyana Howe } \\
\text { PTERIDACEAE }\end{array}$ & 50 & 50 & 50 & 50 & 100 & 25 \\
\hline $\begin{array}{l}\text { Acrostichum danaeifolium Langsd. \& Fisch. } \\
\text { ALISMATACEAE }\end{array}$ & 25 & 25 & 25 & 25 & 25 & 25 \\
\hline Echinodorus aschersonianus Graebn. & 50 & 25 & 25 & 25 & 25 & 25 \\
\hline $\begin{array}{l}\text { Echinodorus bolivianus (Rusby) Holm-Niels } \\
\text { AMARANTHACEAE }\end{array}$ & 25 & 25 & 25 & 25 & 25 & 25 \\
\hline $\begin{array}{l}\text { Gomphrena elegans Mart. } \\
\text { APIACEAE }\end{array}$ & 100 & 100 & 100 & 100 & 100 & 100 \\
\hline $\begin{array}{l}\text { Hydrocotyle leucocephala Cham. \& Schltdl. } \\
\text { CONVOLVULACEAE }\end{array}$ & - & 25 & 25 & 25 & 25 & - \\
\hline $\begin{array}{l}\text { Ipomoea alba L. } \\
\text { CYPERACEAE }\end{array}$ & 25 & 25 & 50 & 50 & 25 & - \\
\hline $\begin{array}{l}\text { Rhynchospora corymbosa (L.) Britton } \\
\text { HALORAGACEAE }\end{array}$ & 100 & 100 & 100 & 100 & 75 & 100 \\
\hline $\begin{array}{l}\text { Myriophyllum aquaticum (Vell.) Verdc. } \\
\text { NYMPHAEACEAE }\end{array}$ & 50 & 50 & 50 & 75 & 50 & 50 \\
\hline $\begin{array}{l}\text { Nymphaea gardneriana Planch. } \\
\text { ONAGRACEAE }\end{array}$ & 50 & 50 & 50 & 50 & 50 & 50 \\
\hline $\begin{array}{l}\text { Ludwigia peruviana (L.) H. Hara } \\
\text { POLYGONACEAE }\end{array}$ & 100 & 100 & 75 & 75 & 75 & 75 \\
\hline $\begin{array}{l}\text { Polygonum cf. acumminatum Kunth } \\
\text { PONTEDERIACEAE }\end{array}$ & - & - & - & - & - & 25 \\
\hline Heteranthera zosterifolia Mart. & 25 & 25 & 25 & 25 & - & - \\
\hline $\begin{array}{l}\text { Pontederia parviflora Alexander } \\
\text { POTAMOGETONACEAE }\end{array}$ & 25 & 25 & - & 25 & 25 & - \\
\hline $\begin{array}{l}\text { Potamogeton illinoensis Morong } \\
\text { SCROPHULARIACEAE }\end{array}$ & 25 & 25 & 25 & 25 & 25 & 25 \\
\hline $\begin{array}{l}\text { Bacopa australis V.C.Souza } \\
14 \text { famílias/17 espécies }\end{array}$ & - & - & 25 & 25 & - & - \\
\hline
\end{tabular}




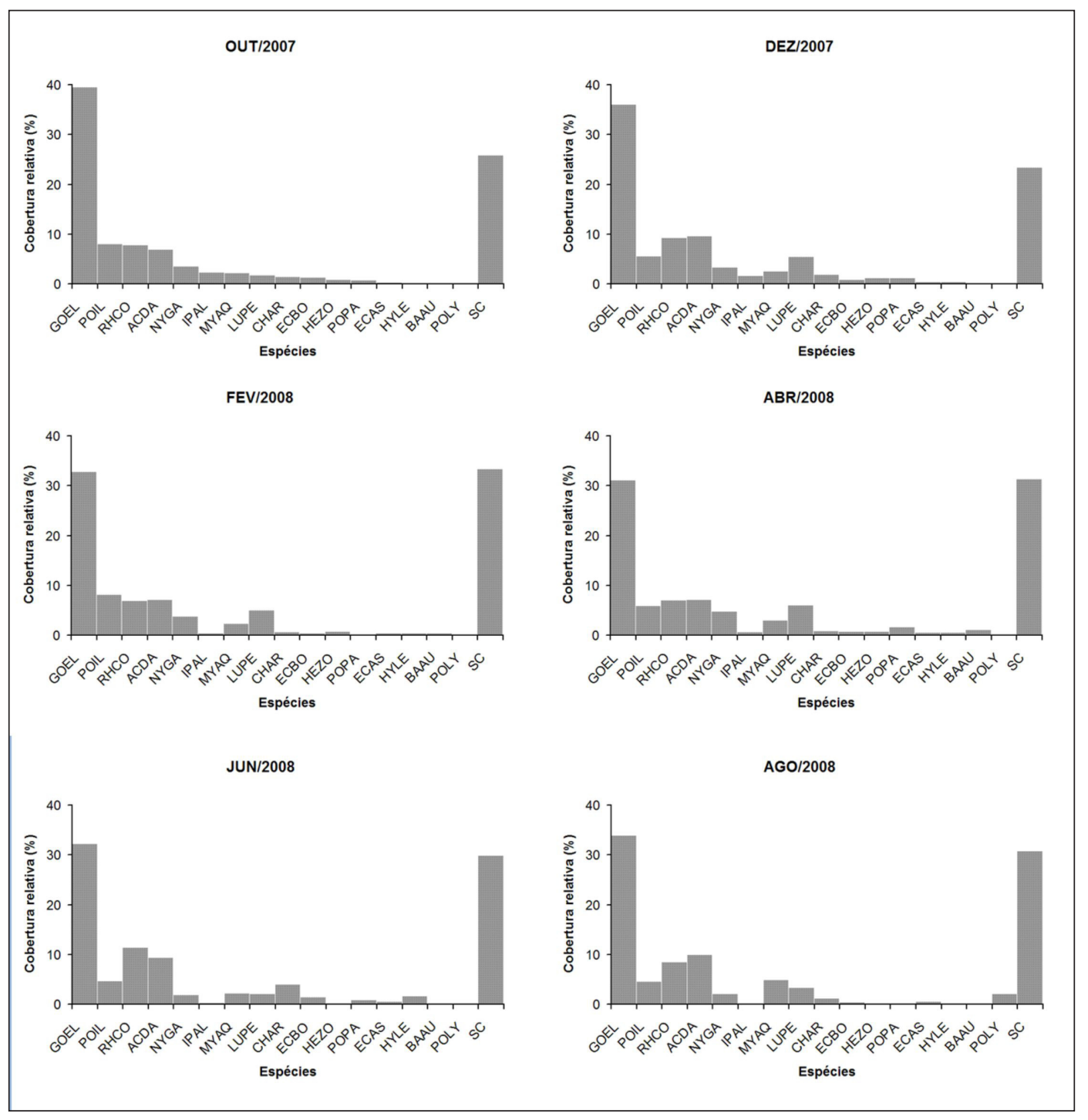

Figura 3. Composição e cobertura relativa (\%) das espécies de macrófitas aquáticas durante o monitoramento no rio Sucuri, RPPN Fazenda São Geraldo, Bonito, MS. (GOEL: Gomphrena elegans, POIL: Potamogeton illinoensis, RHCO: Rhynchospora corymbosa,ACDA: Acrostichum danaeifolium, NYGA: Nymphaea gardneriana, IPAL: Ipomoea alba, MYAQ: Myriophyllum aquaticum, LUPE: Ludwigia peruviana, CHAR: Chara fibrosa e Chara rusbyana, ECBO: Echinodorus bolivianus, HEZO: Heteranthera zosterifolia, POPA: Pontederia parviflora, ECAS: Echinodorus aschersonianus, HYLE: Hydrocotyle leucocephala, BAAU: Bacopa australis, POLY: Polygonum cf. acumminatum, SC: Sem cobertura). Os nomes científicos estão redigidos conforme o Catálogo de Plantas e Fungos do Brasil (FORZZA et al., 20I0). 
o rio (G. elegans Mart. e R. corymbosa (L.) Britton) e, de um modo geral, são as espécies dominantes da comunidade. Estas espécies apresentam hábito do tipo emergente, crescendo às margens do rio. Outras espécies apresentam menor frequência, às vezes ocorrendo de modo pontual como Bacopa australis V.C.Souza e Pontederia parviflora Alexander. A distribuição de tais macrófitas não pode ser notada em toda a extensão do rio Sucuri, apresentam pequenos valores de cobertura relativa e, ainda, predominantemente hábito submerso fixo, com manchas crescendo no leito do rio.

\section{Padrão de desbaste e ecoturismo}

A tabela 2 apresenta o resultado da coleta ramos desbastados de macrófitas aquáticas encontradas presos aos obstáculos naturais do rio (galhos, raízes, troncos, etc.). Somente Echinodorus tenellus (Mart.) Buchenau não havia sido detectada nas amostragens realizadas nas linhas permanentes. O número de espécies encontradas nas coletas variou de 11 a 13 durante o período de estudo.

Observando o padrão de frequência de ocorrência de desbaste de macrófitas aquáticas pode-se propor dois grupos (Tabela 2). O primeiro é composto pelas espécies infrequentes, que foram desbastadas de modo irregular no período e que, segundo os dados de cobertura apresentados, abriga espécies de pequena cobertura relativa na comunidade.

O segundo grupo é composto pelas espécies comuns, que foram desbastadas durante todo o período do estudo. As espécies comuns mostram certa variação entre elas quanto aos valores de cobertura relativa, ou seja, o grupo compreende de G. elegans Mart., a espécie dominante em todo o período, até espécies menos expressivas em termos de cobertura na comunidade como $P$. illinoensis Morong e P. parviflora Alexander.

\section{Composição de espécies e variação na cobertura relativa}

Pott (1999) e Pott e Pott (2000b) listam de um total de 23 espécies de macrófitas aquáticas para o rio Sucuri, assim, foi considerado que os resultados aqui apresentados representam de modo aproximado a composição de espécies de macrófitas aquáticas local. As seis espécies de macrófitas aquáticas não amostradas neste estudo devem apresentar distribuição pontual e pequena cobertura relativa no rio Sucuri.

Pott e Pott (2000a) argumentam que é esperado que a comunidade de macrófitas aquáticas de um dado ecossistema apresente uma dinâmica na qual se observe a variação nos valores composição e cobertura das espécies em um curto período de tempo. Pitelli et al. (2008) demonstraram este padrão ecológico para um reservatório, mostrando que mesmo em ambientes artificiais, onde há um controle artificial da altura da lâmina d'água que evita pulsos de inundação, a composição e cobertura relativas das espécies apresenta variação espacial e temporal. Portanto, outros agentes além da inundação são os responsáveis por esta variação. Estudos futuros devem ser realizados para elucidar o mecanismo por trás deste fenômeno.

No rio Sucuri, a variação sazonal na altura da lâmina d'água do rio (Figura 2), a dinâmica de deposição de sedimentos e o comportamento dos turistas provavelmente estão relacionadas com a dinâmica da comunidade de macrófitas aquáticas, contudo estudos específicos são necessários para 
Tabela 2. Espécies de macrófitas aquáticas amostradas pela coleta de desbastes e seus hábitos. Coletas realizadas ao longo do monitoramento do rio Sucuri (out/2007-ago/2008), RPPN Fazenda São Geraldo, Bonito, MS. (SF:Submersa fixa, EM:Emergente, EP: Epífita, FF: Flutuante fixa,). Os nomes científicos estão redigidos conforme o Catálogo de Plantas e Fungos do Brasil (FORZZA et al., 20I0). Os hábitos são dados por observação em campo e POTT (1999) e POTT e POTT (2000b).

\begin{tabular}{|c|c|c|c|c|c|c|c|}
\hline \multirow{2}{*}{ Espécies } & \multicolumn{6}{|c|}{ coleta de ramo desbastado } & \multirow{2}{*}{ Hábito } \\
\hline & $\overline{\text { out }}$ & dez & fev & abr & jun & Ago & \\
\hline \multicolumn{8}{|l|}{ CHAROPHYCEAE } \\
\hline $\begin{array}{l}\text { Chara fibrosa C. Agardh ex Bruzelius } \\
\text { emend R.D. Wood }\end{array}$ & $\mathrm{X}$ & $\mathrm{X}$ & $\mathrm{X}$ & $\mathrm{X}$ & $X$ & $X$ & SF \\
\hline $\begin{array}{l}\text { Chara rusbyana Howe } \\
\text { ALISMATACEAE }\end{array}$ & $\mathrm{X}$ & $\mathrm{X}$ & $\mathrm{X}$ & $\mathrm{X}$ & $X$ & $\mathrm{X}$ & $\mathrm{SF}$ \\
\hline Echinodorus aschersonianus Graebn. & - & - & $\mathrm{X}$ & - & $\mathrm{X}$ & - & EM \\
\hline $\begin{array}{l}\text { Echinodorus bolivianus (Rusby) Holm- } \\
\text { Niels }\end{array}$ & $X$ & $\mathrm{X}$ & $\mathrm{X}$ & $\mathrm{X}$ & $\mathrm{X}$ & $X$ & SF \\
\hline $\begin{array}{l}\text { Echinodorus tenellus (Mart.) Buchenau } \\
\text { AMARANTHACEAE }\end{array}$ & - & - & - & - & $\mathrm{X}$ & - & $\mathrm{SF}$ \\
\hline $\begin{array}{l}\text { Gomphrena elegans Mart. } \\
\text { APIACEAE }\end{array}$ & $X$ & $\mathrm{X}$ & $\mathrm{X}$ & $\mathrm{X}$ & $X$ & $X$ & EM \\
\hline $\begin{array}{l}\text { Hydrocotyle leucocephala Cham. \& Schltdl. } \\
\text { CONVOLVULACEAE }\end{array}$ & - & $\mathrm{X}$ & $\mathrm{X}$ & $\mathrm{X}$ & - & $\mathrm{X}$ & $\mathrm{SF}$ \\
\hline $\begin{array}{l}\text { Ipomoea alba L. } \\
\text { HALORAGACEAE }\end{array}$ & $\mathrm{X}$ & - & - & - & - & - & $\mathrm{EP}$ \\
\hline $\begin{array}{l}\text { Myriophyllum aquaticum (Vell.) Verdc. } \\
\text { NYMPHAEACEAE }\end{array}$ & $\mathrm{X}$ & $\mathrm{X}$ & $\mathrm{X}$ & $\mathrm{X}$ & $\mathrm{X}$ & $\mathrm{X}$ & $\mathrm{SF}$ \\
\hline $\begin{array}{l}\text { Nymphaea gardneriana Planch. } \\
\text { ONAGRACEAE }\end{array}$ & $\mathrm{X}$ & $\mathrm{X}$ & $\mathrm{X}$ & $X$ & $\mathrm{X}$ & $\mathrm{X}$ & $\mathrm{SF}$ \\
\hline $\begin{array}{l}\text { Ludwigia peruviana (L.) H. Hara } \\
\text { PONTEDERIACEAE }\end{array}$ & $\mathrm{X}$ & - & $\mathrm{X}$ & - & - & $\mathrm{X}$ & EM \\
\hline Heteranthera zosterifolia Mart. & $\mathrm{X}$ & $\mathrm{X}$ & $\mathrm{X}$ & $\mathrm{X}$ & $X$ & $\mathrm{X}$ & $\mathrm{SF}$ \\
\hline $\begin{array}{l}\text { Pontederia parviflora Alexander } \\
\text { POTAMOGETONACEAE }\end{array}$ & $\mathrm{X}$ & $\mathrm{X}$ & $\mathrm{X}$ & $\mathrm{X}$ & $\mathrm{X}$ & $\mathrm{X}$ & EM \\
\hline $\begin{array}{l}\text { Potamogeton illinoensis Morong } \\
\text { SCROPHULARIACEAE }\end{array}$ & $\mathrm{X}$ & $\mathrm{X}$ & $\mathrm{X}$ & $\mathrm{X}$ & $X$ & $\mathrm{X}$ & $\mathrm{SF}$ \\
\hline Bacopa australis V.C.Souza & $X$ & $\mathrm{X}$ & $\mathrm{X}$ & $\mathrm{X}$ & $\mathrm{X}$ & $X$ & $\underline{\mathrm{SF}}$ \\
\hline Total & 12 & 11 & 13 & 11 & 12 & 12 & \\
\hline
\end{tabular}

separar os efeitos de cada um desses agentes ecológicos.

Descrevendo as macrófitas que ocorrem no rio Sucuri, Pott e Pott (2000b) relatam também que a espécie dominante foi G. elegans Mart., com 40\% de cobertura relativa. Contudo, o grupo de espécies com cobertura relativa intermediária apresentou somente uma espécie em comum, $P$. illinoensis Morong. As outras espécies apontadas por estes autores para este grupo foram Ludwigia peruviana (L.) H. Hara e Chara 
rusbyana Howe. Provavelmente a diferença na ordenação das espécies intermediárias entre os estudos deve-se à diferença na metodologia de coleta e na análise de dados. Pott e Pott (2000b) empregaram o uso de estimativas visuais de cobertura, método recorrente na literatura (CARVALHO et al., 2003; PITELLI et al., 2008; MARTINS et al., 2008), mas com grande erro de estimativa por ser dependente da habilidade de cada avaliador. Outra diferença que pode ser apontada refere-se aos limites da área de estudo, pois, o levantamento de campo relatado aqui ocorreu em quatro linhas com distribuição sistemática, enquanto o trabalho de Pott e Pott (2000b) procurou cobrir toda a extensão do rio.

A parte da lâmina d'água do rio Sucuri livre de macrófitas variou entre 23$33 \%$, demonstrando que a superfície do rio é dominada por macrófitas, as quais criam considerável complexidade ambiental permitindo a ocorrência de muitas espécies de animais associados, entre eles: peixes, insetos, moluscos e crustáceos (FROEHLICH, 1999). A variação de tamanho da área livre de macrófitas está relacionada à flutuação da altura da lâmina d'água do rio Sucuri, que por sua vez é afetada pela sazonalidade do clima regional, marcado por uma estação de chuva e outra de estiagem (COSTACURTA, 2005).

$A$ variação na cobertura relativa e na frequência das espécies ao longo do rio provavelmente é resultado da dinâmica de colonização de cada espécie, envolvendo mecanismos de reprodução (DOMINGOS et al., 2005; NEVES e SANTOS, 2008) e competição por espaço (HENRY-SILVA e CAMARGO, 2005). Considerando estas estratégias, pode-se afirmar que perturbações de pequena escala espacial e intermitentes são de primordial importância para a manutenção da maior biodiversidade possível de macrófitas aquáticas no ecossistema estudado.

\section{Padrão de desbaste e seleção de espécies com potencial para indicação de impactos ambientais do ecoturismo: perspectivas}

O hábito da macrófita aquática não tem efeito na frequencia de desbastes, pois espécies com diferentes formas de colonização - epífitas, emergentes e submersas fixas perderam ramos durante o estudo. A altura da coluna d'água deve exercer um pequeno efeito sobre a frequência de desbaste das macrófitas aquáticas, pois durante os meses de cheia do rio - outubro a fevereiro - não foi observado um grande aumento no número de espécies desbastadas quando comparado com os meses de vazante do rio - abril a agosto. Assim, é esperado que outros agentes que sejam constantes no ano expliquem melhor os desbastes de macrófitas.

A produção de biomassa em macrófitas aquáticas tende a ser constante ao longo do ano (OLIVEIRA et al., 2005), portanto, pode-se descartar a hipótese de produção sazonal de ramos vegetativos. A hipótese alternativa apresentada é relacionada à atividade turística que ocorre no rio Sucuri, porém os dados de frequência de ocorrência de ramos desbastados para as espécies não são úteis para o teste. Sugere-se a execução de outra coleta de dados na qual seriam medidos a massa (g) de macrófitas desbastadas e sua correlação com o número de turistas que realizam a flutuação. Assim, nos períodos de alta temporada, quando há um expressivo aumento no número de visitantes, é esperado um aumento na biomassa de macrófitas aquáticas desbastadas. Por sua vez, nos 
períodos de baixa temporada, quando o número de turistas é consideravelmente menor, é esperada a redução na biomassa de macrófitas aquáticas desbastadas, independentemente das espécies.

As espécies que apresentaram menor cobertura relativa, frequência irregular e predominantemente hábito submerso fixo são justamente as espécies com manchas de colonização crescendo no leito do rio, em constante contato com os turistas que flutuam nas águas do rio Sucuri. Aparentemente, o contato com os turistas, barcos e remos, associados ao caráter friável do substrato do leito do rio Sucuri ameaçam a viabilidade das populações destas espécies de macrófitas aquáticas, as quais estão sujeitas ao desbaste ou perda de manchas inteiras (POTT e POTT 2000b). Assim, duas são as características que as espécies de macrófitas aquáticas devem apresentar para serem eleitas como indicadoras dos impactos da atividade de flutuação no rio Sucuri: 1) pequena cobertura relativa, pois a perda de uma mancha de colonização significa uma impactante redução da população da espécie, e, 2) hábito submerso fixo, pois sobre parte das manchas destas espécies se dá o trânsito de barcos e turistas. As espécies que não possuírem estas características serão raramente afetadas pela atividade de flutuação, de modo que não serviriam para indicar a existência de impactos no ecossistema do rio Sucuri.

Uma condição para a escolha do indicador ecológico do monitoramento dos impactos ecológicos do ecoturismo no rio Sucuri é a frequência de ocorrência nas linhas de amostragem. Assim, as espécies escolhidas como indicadores ecológicos devem ainda ser encontradas ao menos em 50\% das linhas de amostragem estabelecidas ao longo do curso do rio. Isto é necessário para que a espécie seja sempre detectável, condição primordial para a execução do monitoramento dos impactos ambientais.

Os resultados de cobertura relativa, frequência de ocorrência e de desbaste apresentados aqui permitem eleger duas espécies de macrófitas aquáticas para a indicação de impactos da atividade turística no rio Sucuri. São elas Nymphaea gardneriana Planch.e Myriophyllum aquaticum (Vell.) Verdc. A espécie $N$. gardneriana Planch. também foi listada por Pott e Pott (2000b) como indicadora de impacto ambiental, por ser sensível a distúrbios mecânicos, como remadas.

\section{Considerações Finais}

É sugerido que o monitoramento dos impactos do turismo no rio Sucuri sobre as macrófitas aquáticas seja realizado na sua organização biológica populacional. Desta forma, é reduzida a dimensionalidade de fatores externos que afetam a dinâmica de colonização e cobertura de uma dada espécie (NIEMI; MCDONALD, 2004), possibilitando um ajuste mais fino da capacidade de suporte do passeio turístico para garantir a sustentabilidade ambiental da atividade na RPPN Fazenda São Geraldo.

\section{Agradecimentos}

Os autores agradecem à Associação de Proprietários de RPPNs do Estado de Mato Grosso do Sul (REPAMS) e CI-Brasil pelo financiamento do estudo (Programa de Incentivo às RPPNs do Pantanal - edital 1/2006); ao sr. Geraldo Majella Pinheiro, proprietário da Fazenda São Geraldo, pelo apoio logístico necessário ao estudo; aos revisores pelas valiosas considerações, ao Carlos Eduardo Pena Jr, pela revisão do abstract. 


\section{Referências}

BENTO, L.; MAROTTA, H.; ENRICH-PRAST, A. O papel das Macrófitas Aquáticas Emersas no Ciclo do Fósforo em Lagos Rasos. Oecologia Brasiliensis, Rio de Janeiro, v. 11, n.4, p.582-589, 2007.

BOGGIANI,P.C. Geologia da Bodoquena. In: SCREMIN-DIAS, E.; POTT, V.J.; HORA, R. C.; SOUZA, P. R.; (AA.). BOGGIANI, P. C.; FROEHLICH, O. (Participação). Nos jardins submersos da Bodoquena: guia para identificação de plantas aquáticas de Bonito e região. Campo Grande: Ecoa e Universidade Federal de Mato Grosso do Sul, 1999. p. 10-23.

BRASIL. Ministério de Minas e Energia. Secretaria-Geral. Projeto RADAMBRASIL: Folha SF-21 (Campo Grande). Rio de Janeiro, 1982. 412 p. (Levantamento dos Recursos Naturais, v.28).

BROWER,J.E.; ZAR,J.H.; von ENDE, C. N. Field and Laboratory Methods for General Ecology. 4. ed. Boston: WCB/McGraw-Hill, 1997.

CANFIELD, R. Application of line interception in sampling range vegetation. Journal of Forestry, v.39, n.4, p.388-394, 1941.

CARVALHO, F.T.; VELINI, E. D.; CAVENAGHI, A. L.; NEGRISOLI, E.; CASTRO, R. M. Influência da turbidez da água do rio Tietê na ocorrência de plantas aquáticas. Planta Daninha, Viçosa, v.23, n.2, p.359-362, 2005.

CARVALHO, F.T.; GALO, M. L. B.T.; VELINI, E. D.; MARTINS, D. Plantas aquáticas e nível de infestação das espécies presentes no reservatório de Barra Bonito, no rio Tiête. Planta Daninha, Viçosa, v.21, Ed. Especial, p.15-19, 2003.

CAVENAGHI, A. L.; VELINI, E. D.; NEGRISOLI, E.; CARVALHO, F.T.; GALO, M. L. B. T.; TRINDADE, M. L. B.; CORREA, M. R.; SANTOS, S. C. A. Monitoramento de problemas com plantas aquáticas e caracterização da qualidade de água e sedimento na UHE Mogi-Guaçu. Planta Daninha, Viçosa, v. 23, n.2, p.225-231, 2005.

COSTACURTA, M. B. Subsídios para a elaboração do plano de manejo da Reserva Particular do Patrimônio Natural (RPPN) Fazenda São Geraldo, município de Bonito, Mato Grosso do Sul. 2005. [S.I.], Dissertação (Mestrado em Meio Ambiente e Desenvolvimento Regional) - Universidade para o Desenvolvimento do Estado e da Região do Pantanal, UNIDERP, Campo Grande, 2005.

DOMINGOS, V. D.; PASCHOA, P. L.; MARTINS, D.; COSTA, N. V. Alocação de biomassa e nutrientes em Myriophyllum aquaticum sob diferentes níveis de macronutrientes. Planta Daninha, Viçosa, v. 23, n.2, p.193-201, 2005.

DURIGAN, G. Métodos para análise de vegetação arbórea. In: CULLEN Jr, L.; 
VALLADARES-PADUA, C.; RUDRAN, R. (Org.). Métodos de estudos em biologia da conservação e manejo da vida silvestre. Curitiba: UFPR, Curitiba: 2003. p. 455-480. (Fundação O Boticário de Proteção à Natureza).

FELFILI, J. M.; CARVALHO, F. A.; HAIDAR, R. F. Manual para o monitoramento de parcelas permanentes nos biomas Cerrado e Pantanal. Brasília: Universidade de Brasília, 2005. 51p. (Faculdade de Tecnologia - Departamento de Engenharia Florestal).

FORZZA, R. C.; LEITMAN, P. M.; COSTA, A.; CARVALHO JR, A. A.; PEIXOTO, A. L.; WALTER, B. M. T.; BICUDO, C.; ZAPPI, D.; COSTA, D. P.; LLERAS, E.; MARTINELLI, G.; LIMA, H. C.; PRADO, J.; STEHMANN, J. R.; BAUMGRATZ, J. F. A.; PIRANI,J. R.; SYLVESTRE,L.S.; MAIA, L. C.; LOHMANN,L.G.; PAGANUCCI, L.; SILVEIRA, M.; NADRUZ, M.; MAMEDE, M.C. H.; BASTOS, M. N.; MORIM, M. P.; BARBOSA, M. R.; MENEZES, M.; HOPKINS, M.; SECCO, R.; CAVALCANTI,T.; SOUZA, V. C. Catálogo de plantas e fungos do Brasil. Rio de Janeiro: Andrea Jakobsson Estúdio: Instituto de Pesquisas Jardim Botânico do Rio de Janeiro, 2010. 1699 p. 2.v.: il.

FROEHLICH, O. Muito mais além que alimento. In: SCREMIN-DIAS, E.; POTT, V. J.; HORA, R. C.; SOUZA, P. R.; (AA.). BOGGIANI, P. C.; O. FROEHLICH, O. (Participação). Nos jardins submersos da Bodoquena: guia para identificação de plantas aquáticas de Bonito e região. Campo Grande: Ecoa e Universidade Federal de Mato Grosso do Sul, 1999. [S.I.].

HENRY-SILVA, G. G.; CAMARGO, A. F. M. Interações ecológicas entre as macrófitas aquáticas flutuantes Eichhornia crassipes e Pistia stratiotes. Hoehnea, São Paulo, v.32, n. 3, p. $445-452,2005$.

IRGANG, B. E.; GASTAL Jr, C. V. S. Macrófitas aquáticas da planície costeira do Rio Grande do Sul. 1.ed. Porto Alegre: UFRGS, 1996.

MARTELLO, A. R.; NUNES, I. G. W.; BOELTER, R. A.; LEAL, L. A. Malacofauna límnica associada à macrófitas aquáticas do rio Iguariaçá, São Borja, RS, Brasil. Ciência e Natura, Santa Maria, v.30, n.1, p.27-41, 2008.

MARTINS, D.; COSTA, N. V.; TERRA, M. A.; MARCHI, S. R. Caracterização da comunidade de plantas aquáticas de dezoito reservatórios pertencentes a cinco bacias hidrográficas do estado de São Paulo, Brasil.Planta Daninha, Viçosa,v.26, n. 1, p.17-32, 2008.

MARTINS, D.; VELINI, E. D.; PITELLI, R. A.; TOMAZELLA, M. S.; NEGRISOLI, E. Ocorrência de plantas aquáticas nos reservatórios da Light-RJ. Planta Daninha, Viçosa, v.21, Edição Especial, p.105-108, 2003.

MENDES, C. A. B.; GRHES, S. A.; MARTINS-JUNIOR, A. Bacia Hidrográfica do Rio Miranda: Estado da Arte. 2003. Cidema/WWF. Documento para subsidiar as discussões no workshop "Estado da Arte da Bacia Hidrográfica do Rio Miranda", em Bonito- MS, de 13 a 15 de agosto de 2003. 31 p. Disponível em: <http://www.wwf.org.br/projetos/doc/ workshopmiranda_resumo_estadodaarte.pdf $>$. Acesso em: 5 fev. 2005. 
NEVES, A. C.; SANTOS, F. A. M. Nem tudo são flores no Pantanal. Ciência Hoje, [S.I.], v.41, n. 245, p.71-73, 2008.

NIEMI, G. J.; McDONALD, M. E. Application of ecological indicators. Annual Review of Ecology, Evolution, and Systematics, v.35, n.1, p.89-111, 2004.

OLIVEIRA, A. K. M.; FAVERO, S.; COSTACURTA, M. B. Variação temporal da biomassa de Eichhornia azurea (Sw.) Kunth (Pontederiaceae) e macrófitas aquáticas associadas em uma lagoa do Rio Negro, pantanal do Rio Negro, Mato Grosso do Sul. Natureza On Line, Santa Teresa, v.3, n.1, p.7-12, 2005.

PEIRÓ, D. F.; ALVES, R. G. Insetos aquáticos associados a macrófitas da região litoral da represa do Ribeirão das Anhumas (município de Américo Brasiliense, São Paulo, Brasil). Biota Neotropica, Campinas, v.6, n.2, p. 1-9, 2006.

PITELLI, R. L.C.M.; TOFFANELI, C.M.; VIEIRA, E. A.; PITELLI, R. A.; VELINI, E. D. Dinâmica da comunidade de macrófitas aquáticas no reservatório de Santana, RJ. Planta Daninha, Viçosa, v.26, n.3, p.473-480, 2008.

POMPEO, M. Monitoramento e manejo de macrófitas aquáticas. Oecologia Brasiliensis, Rio de Janeiro, v.12, n. 3, p.406-424, 2008.

POTT, V.J. Plantas aquáticas da Bodoquena. In: SCREMIN-DIAS, E.; POTT, V.J.; HORA, R. C.; SOUZA, P. R. (AA.). BOGGIANI. P. C.; FROEHLICH, O. (Participação). Nos jardins submersos da Bodoquena: guia para identificação de plantas aquáticas de Bonito e região. Campo Grande: Ecoa e Universidade Federal de Mato Grosso do Sul, 1999. [S.I.].

POTT, V. J.; POTT, A. Plantas Aquáticas do Pantanal. Brasília: EMBRAPA, 2000a. (Comunicação para a Transferência de Tecnologia)

POTT, V. J.; POTT, A. Subsídios à conservação da vegetação aquática de rios de Bonito, MS: caso do rio Sucuri. In: SIMPÓSIO SOBRE RECURSOS NATURAIS E SÓCIOECONÔMICOS DO PANTANAL: Os desafios do novo milênio. 3., 2000, Corumbá. Anais... Corumbá: Embrapa Pantanal, 2000b. p. 1-12.

REATTO, A.; CORREA, J. R.; SPERA, S.T. Solos do Bioma Cerrado: aspectos pedológicos. In: SANO, S. M.; ALMEIDA, S. P. (Ed.). Cerrado: ambiente e flora. Planaltina: EmbrapaCPAC, 1998. cap. 3, p. 47-86.

ROCHA, C. G.; RESENDE, U. M.; LUGNANI, J. S. Diversidade de macrófitas em Ambientes aquáticos do IPPAN na Fazenda Santa Emília, Aquidauana, MS. Revista Brasileira de Biociências, Porto Alegre, v.5, Supl. 2, p.456-458, 2007. (57o Congresso Nacional de Botânica). 
SCREMIN-DIAS, E. O retorno à origem aquática. In: SCREMIN-DIAS, E.; POTT, V.J.; HORA, R. C.; SOUZA, P.R.(AA.). BOGGIANI.P. C.; FROEHLICH, O. (Participação). Nos jardins submersos da Bodoquena: guia para identificação de plantas aquáticas de Bonito e região. Campo Grande: Ecoa e Universidade Federal de Mato Grosso do Sul, 1999. [S.I.].

THOMAS, S. M.; BINI, L. M. Análise crítica dos estudos sobre macrófitas aquáticas desenvolvidos no Brasil. In: THOMAS, S. M.; BINI, L. M. (Ed.) Ecologia e manejo de macrófitas aquáticas. Maringá: EDUEM, 2003. p. 19-38. 